\title{
TECHNIQUE OF SERIAL ENDOMETRIAL BIOPSY IN THE MONKEY THROUGH A UTERO-CUTANEOUS FISTULA
}

\author{
ROBERT G. GOOD AND DEAN L. MOYER \\ Departments of Obstetrics and Gynecology and of Pathology, Harbor General Hospital, \\ Torrance, California, and University of California, Los Angeles \\ (Received 5th April 1966)
}

\begin{abstract}
Summary. A method for the creation of an abdominal utero-cutaneous fistula in the monkey is described. This surgical technique provides a means for serial endometrical biospy and observation of histological response.
\end{abstract}

Serial evaluation of the human endometrium by transcervical suction biopsy has recently found widespread use. Biopsy by this technique permits accurate evaluation of the effects of sex steroids, determination of pathological endometria and timing of ovulation. In the rhesus monkey, however, the tortuous endocervical canal resulting from a prominent cervical colliculus (Wislocki, 1933) prevents successful endometrial biopsy. Previous investigations have, for the most part, relied on hysterectomy in order to obtain endometrial samples for study. Recently both Martin \& Eckstein (1966) and Mastroianni \& Rosseau (1965) have published studies demonstrating techniques of transcervical cannulation of the monkey uterus, but neither method lends itself to dependable biopsy. Van Wagenen \& Morse (1940) first described a technique for the formation of a partially exteriorized uterus in the monkey. In two of these preparations they were able to observe cyclic anatomical variations in the uterus and to obtain endometrial curettings.

In our laboratory we have recently developed a technique for preparing a chronic utero-cutaneous abdominal fistula which permits repeated suction biopsy of the endometrium in the unanaesthetized monkey. This communication gives an outline of the technique and of its successful application.

The anaesthetized female monkey is placed on the operating table in a supine position. The lower abdomen is surgically opened midway between the umbilicus and symphysis through a 7 to $8 \mathrm{~cm}$ vertical incision. The uterine fundus is then grasped in a Babcock clamp and the serosal surface of the fundus elevated to the level of the skin incision at its lowest border. The anterior peritoneum is then closed circumferentially about the mid-segment of the corpus so that sutures unite peritoneum and serosa at the lower border of the peritoneal incision. The remainder of the peritoneal incision is closed in the 
usual fashion. Fascia of the anterior rectus sheath is similarly sutured to serosa at a more superficial site. Both peritoneum and rectus sheath now support the uterus so that the fundus lies at the level of the skin incision (Pl. 1, Fig 1). A core of myometrium measuring 7 to $10 \mathrm{~mm}$ in diameter is then sharply removed to expose the uppermost portion of the endometrial cavity. The skin incision is closed taking care to unite the myometrium to the adjacent abdominal skin. When closure is complete the utero-cutaneous fistula so formed may easily be sounded to a depth of 2.5 to $5.0 \mathrm{~cm}$. All suturing is carried out with $2 / 0$ chromic catgut suture material.

Following formation, the fistula must be sounded once or twice weekly in order to maintain patency. Healing readily occurs, leaving a fistulous tract with an inconspicuous abdominal opening. Neither herniation nor retraction of the uterus has occurred in ten of these preparations used regularly over a 6 -month period. Mucus of endometrial origin is often visible at the abdominal opening and menstruation regularly occurs through this site. No infections have been observed.

Endometrial biopsy may be carried out with the Rock-Garcia (B-D Laboratories, Inc., Rutherford, New Jersey) or Milex (Milex-Fertilex Company, Los Angeles, California) suction curette attached to a $10 \mathrm{ml}$ syringe. The biopsy intrument is passed through the fistula into the uterine cavity (Pl. 2, Fig. 2). By applying suction and gently scraping the uterine cavity, endometrial samples of varying size may be obtained.

Biopsies obtained in the first 3 to 4 weeks following fistula formation are seen to contain numerous acute and chronic inflammatory cells; after this time, however, biopsies are regularly clean and adequate for microscopic interpretation (Pl. 2, Fig. 3) (cf. Bartelmez, Corner \& Hartman, 1951).

Applications of the technique will suggest themselves to investigators studying primate reproductive physiology.

This report has been supported by the Ford Foundation.

\section{REFERENCES}

Bartelmez, G. W., Corner, G. W. \& Hartman, C. G. (1951) Cyclic changes in the endometrium of the rhesus monkey (Macaca mulatta). Contr. Embryol. Carnegie Instn., 34, 99.

Martin, C. B. \& Eckstein, P. (1966) Transcervical uterine catheterization in rhesus monkeys. Am. $\mathcal{F}$. Obst. Gynec. 94, 514.

Mastrotanni, L. \& Rosseau, C. H. (1965) Influence of the intrauterine coil on ovum transport and sperm distribution in the monkey. Am. F. Obst. Gynec. 93, 416.

VAN WAGENEN, G. \& Morse, A. H. (1940) Cyclic changes in exteriorized uterus. Endocrinology, 27, 268.

WisLocki, G. B. (1933) The reproductive systems. The Anatomy of the Rhesus Monkey, p. 231. Eds. C. G. Hartman and W. L. Straus, Jr. Williams \& Wilkins, Baltimore. 


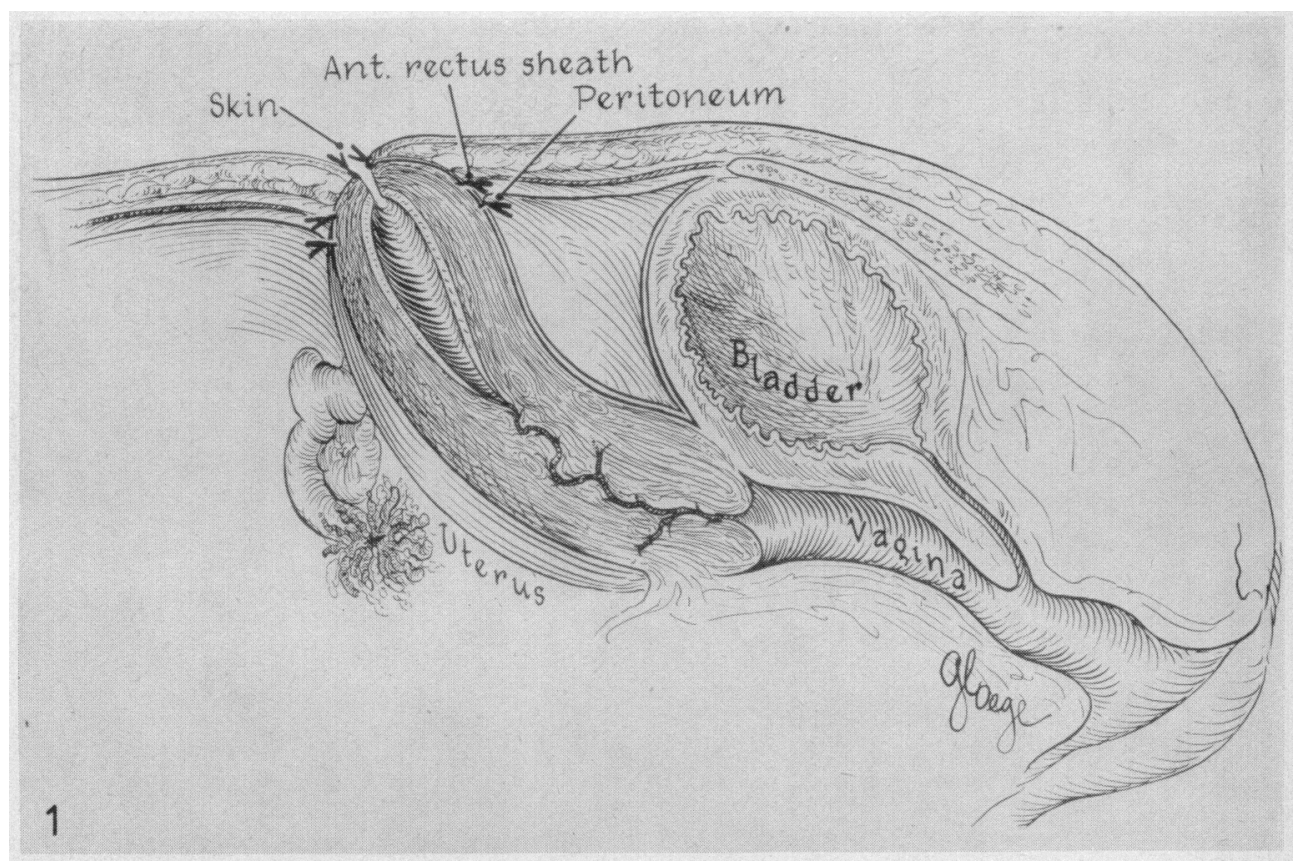

FIG. 1. Diagrammatic illustration of fistula demonstrating uterine supporting structures. 

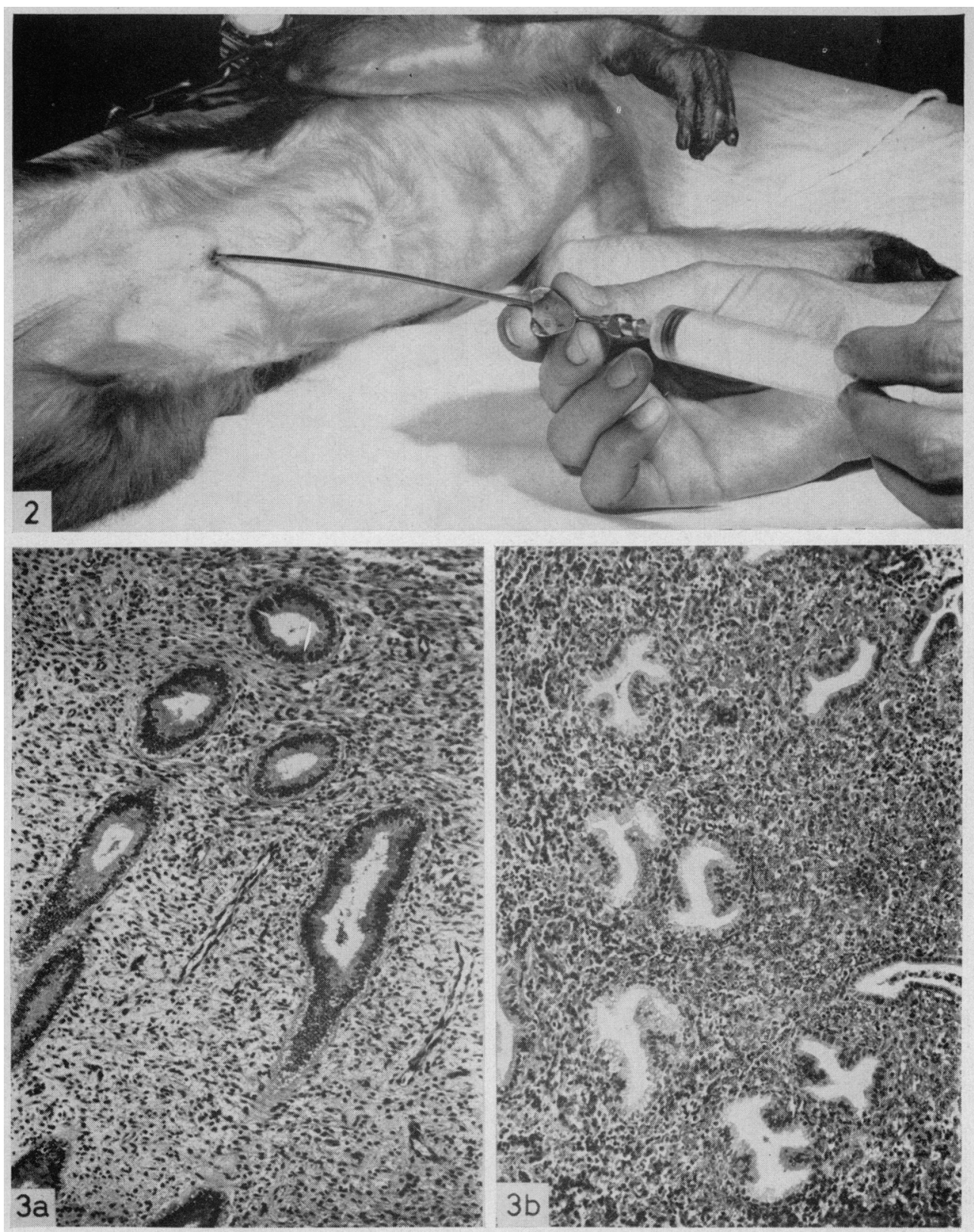

lig. 2. Technique of endometrial biopsy in an unanaestbetized rhesus monkey.

lig. 3. (a) Endometrial biopsy from the carly secretory phase demonstrating subnuclear vacuoles in the glands. $\times 190$. (b) Biopsy in carly menstrual phase showing glandular dilatation with acute and chronic inflammatory cells infiltrating stroma. $\times 100$. 